\title{
Low-Dose Vismodegib as Maintenance Therapy After Locally Advanced Basal Cell Carcinoma Complete Remission: High Efficacy with Minimal Toxicity
}

\author{
Massimiliano Scalvenzi - Milena Cappello · Claudia Costa • \\ Gabriella Fabbrocini · Mariaantonietta Luciano · Alessia Villani
}

Received: March 3, 2020 / Published online: April 2, 2020

(C) The Author(s) 2020

\begin{abstract}
Introduction: Locally advanced basal cell carcinoma (laBCC) has always represented an uncommon, difficult-to-treat form of skin cancer, but approval of the Hedgehog inhibitor (HHI) vismodegib has provided an effective, well-tolerated therapy. While this drug has been shown to be a safe and effective during treatment, to date the effect of its prolonged use at a low dose after complete remission (CR) of laBCC has not been described. The aim of this study was to report our experience regarding the long-term efficacy of low-dose vismodegib as maintenance therapy in patients with CR of the disease during a 1-year follow-up period.

Methods: An observational retrospective study was conducted at the Non-Melanoma Skin Cancer Unit of the University of Federico II (Naples). Patients who reported complete regression of their advanced BCC after vismodegib treatment were included in the study and subsequently separated into two groups. One group of patients continued with the "drug
\end{abstract}

Digital Features To view digital features for this article go to https://doi.org/10.6084/m9.figshare.11980353.

M. Scalvenzi - M. Cappello - C. Costa ·

G. Fabbrocini · M. Luciano · A. Villani ( $\square)$

Dermatology Unit, Department of Clinical Medicine

and Surgery, Federico II University of Naples,

Naples, Italy

e-mail: ali.vil@hotmail.it holiday" regimen consisting of a once-weekly maintenance dosage of $150 \mathrm{mg}$ vismodegib for 1 year after CR of their BCC; the second group comprised patients who decided not to take a maintenance dosage following complete regression of their BCC.

Results: A total of 42 patients (35 males, 7 females) with a median age of 75.2 years and complete regression of their advanced BCC after treatment with vismodegib were included in the study. Of these, 27 (64\%) patients continued with the "drug holiday" regimen, receiving a once-weekly maintenance dosage of $150 \mathrm{mg}$ vismodegib for 1 year after CR of their BCC, and 15 (36\%) patients decided not to take the maintenance dosage. Patients who continued to receive the low-dose vismodegib treatment did not present any BCC recurrence during 1-year follow-up period, while those who discontinued vismodegib treatment reported a BCC recurrence rate of $26.6 \%$ ( $4 / 15$ patients) during the 1-year follow-up period.

Conclusions: Our retrospective analysis focused on the use of a novel therapeutic scheme based on prolonged use of vismodegib after $\mathrm{CR}$ of the laBCC. The results demonstrate that the maintenance dose of vismodegib described herein effectively eliminated skin tumor recurrence and reduced the severity of common adverse events, thus increasing patient compliance. 
Keywords: Basal cell carcinoma; Low-dose; Treatment; Vismodegib

\section{Key Summary Points}

Locally advanced basal cell carcinoma (laBCC) has alway represented an uncommon, difficult-to-treat form of skin cancer, but approval of the Hedgehog inhibitor (HHI) vismodegib has provided an effective, well-tolerated therapy.

Many different schemes of dose reduction during treatment have been proposed in order to increase patients' compliance and adherence to treatment.

The aim of our clinical study was to assess the data compiled on a single-center' $s$ experience on the long-term efficacy of continuing the treatment of patients with complete remission of the disease with low-dose vismodegib during 1-year follow-up period.

Patients with dose adjustment did not present any recurrence, while recurrence did occur among four patients of the 15 who interrupted their drug treatment after complete remission had been achieved.

\section{INTRODUCTION}

Basal cell carcinoma (BCC) is the most common non-melanoma skin cancer (NMSC) [1]. Although surgery is the first-line therapy for BCC, some cases can progress to an advanced or, very rarely, to a metastatic state, frequently requiring non-surgical approaches, such as cryotherapy, adjuvant radiotherapy, and targeted therapy [2]. Locally advanced BCC (laBCC) has always represented an uncommon, difficultto-treat form of skin cancer, but approval of the Hedgehog inhibitor (HHI) vismodegib in 2012 has provided an effective treatment for patients affected by laBCC and those with metastatic BCC who are ineligible for surgery and/or radiotherapy [3]. Vismodegib selectively connects to the smoothened protein, deactivating the Hedgehog pathway involved in the tumorigenesis process, thus resulting in tumor growth inhibition [4]. The approved dosage of this HHI is $150 \mathrm{mg}$ per day. Although this novel drug has been shown to be a safe and effective drug, usually increasing patients' health-related quality of life [5], some adverse events (AEs) during treatment, such as muscle spasms, dysgeusia, and alopecia, have been described [6]. In order to increase patients' compliance and adherence to treatment, many different schemes of dose reduction during treatment have been proposed $[7,8]$. However, to date, the effect of a prolonged use of low-dose vismodegib, also after complete remission (CR) of the laBCC has been achieved, has not been described. The aim of our clinical study was to report data compiled on a singlecenter's experience on the long-term efficacy of a continuous treatment with a low dose (150 mg/daily, once weekly) of the HHI vismodegib in patients who achieved CR of the disease during a 1-year follow-up period.

\section{METHODS}

An observational retrospective study was conducted at the Non-Melanoma Skin Cancer Unit of the University of Federico II (Naples) from January 2016 to January 2020. Patients who reported complete remission of their advanced BCC after vismodegib treatment $(150 \mathrm{mg} /$ day $)$ were included, following histological confirmation of the complete regression of the BCC. The age, gender, and duration of treatment were recorded for each patients. Once enrolled in the study, the patients were separated in two groups. One group comprised those patients who continued with the "drug holiday" regimen after the complete remission of their BCC, receiving a once-weekly maintenance dosage of $150 \mathrm{mg}$ vismodegib for 1 year. The other group comprised patients who decided to discontinue vismodegib treatment after the complete regression of their BCC because of more severe AEs, such as severe alopecia and muscle pain. All patients were visited by healthcare professionals each month for 1 year. 
All procedures performed in studies involving human participants were in accordance with the 1964 Declaration of Helsinki and its later amendments or comparable ethical standards. Informed consent to participate was obtained from all individual participants included in the study. Ethics committee approval was waived by University of Naples Federico II as this was a retrospective observational study.

\section{RESULTS}

A total of 42 patients (35 males, 7 females) with complete regression of their advanced BCC after vismodegib treatment were included in the study. The median age of the patients was 75.2 (range 43-95) years. All patients included in the study had been treated with vismodegib $(150 \mathrm{mg}$ /day) for a median duration of 7.1 (range 1-22) months, with CR of the tumor. After CR of their BCC, 27 of the $42(64 \%)$ patients continued with the "drug holiday" regimen of a once-weekly maintenance dosage of $150 \mathrm{mg}$ vismodegib for 1 year, whereas the remaining 15 (36\%) patients decided not to take a maintenance dosage after the complete regression of their BCCs due to more severe AEs. Patients who continued vismodegib treatment did not present any BCC recurrence during the 1-year follow-up period; moreover, no AEs were reported, with the exception of mild dysgeusia in $48 \%(13 / 27)$ of patients and mild muscle pain in $29.6 \%(8 / 27)$. In comparison, among patients who had discontinued vismodegib treatment a BCC recurrence rate of $26.6 \%(4 / 15)$ was reported during the 1-year follow-up period and all of the AEs previously reported had disappeared. Three of the patients who presented with recurrence of the disease were treated with surgery ( 2 patients) or 5-fluorouracil topical treatment (1 patient); only one patient agreed to start again on vismodegib treatment.

\section{DISCUSSION}

Basal cell carcinoma is the most common form of skin malignancy worldwide, accounting about $80 \%$ of all NMSCs $[1,2]$. In recent years, vismodegib, a HHI, has been used in the treatment of patients with laBCCs who are ineligible for surgery or radiotherapy and shown promising results [2]. Nevertheless, patients usually report several AEs while receiving vismodegib therapy, and dose adjustments are sometimes required during the therapy to decrease the possibility of the patient discontinuing the treatment and to increase the patient's adherence to therapy [7, 8]. Our retrospective analysis focused on the use of a novel therapeutic scheme based on the prolonged use of low-dose vismodegib after CR of the laBCC; this strategy proved to be effective in eliminating skin tumor recurrence and in reducing the severity of common AEs. Interestingly, we observed that patients with dose adjustment did not present any recurrence, while recurrences were reported in four of the 15 patients who stopped the drug treatment following achievement of CR. To our knowledge, there is no report in the literature of studies describing the continuous use of low-dose vismodegib as maintenance therapy after CR of laBCCs, although different dose adjustment schemes during treatment to manage AEs have been described [8].

It must be noted that our study is limited by its retrospective design and by the fact that the control arm (those stopping maintenance therapy with vismodegib) comprised a small number of patients.

\section{CONCLUSION}

Our preliminary data demonstrate that patients with dose adjustment of vismodegib did not present any recurrence, while $26.6 \%$ of patients who discontinued the drug after CR had been achieved reported a recurrence of the BCC. Further randomized controlled studies involving a larger number of patients are required to better confirm the utiity of a continuous treatment with vismodegib after the CR of BCCs and to define the best treatment strategy for each patient. 


\section{ACKNOWLEDGEMENTS}

Funding. No funding or sponsorship was received for this study or the publication of this article.

Authorship. All named authors meet the International Committee of Medical Journal Editors (ICMJE) criteria for authorship for this manuscript, take responsibility for the integrity of the work as a whole, and have given final approval to the version to be published.

Disclosures. Massimiliano Scalvenzi, Milena Cappello, Claudia Costa, Mariaantonietta Luciano and Alessia Villani have nothing to disclose. Gabriella Fabbrocini is a member of the journal's Editorial Board.

Compliance with Ethics Guidelines. All procedures performed in studies involving human participants were in accordance with the 1964 Declaration of Helsinki and its later amendments or comparable ethical standards. Informed consent to participate was obtained from all individual participants included in the study. Ethics committee approval was waived by the University of Naples Federico II as this was a retrospective observational study.

Data Availability. The datasets during and/ or analyzed during the current study are available from the corresponding author on reasonable request.

Open Access. This article is licensed under a Creative Commons Attribution-NonCommercial 4.0 International License, which permits any non-commercial use, sharing, adaptation, distribution and reproduction in any medium or format, as long as you give appropriate credit to the original author(s) and the source, provide a link to the Creative Commons licence, and indicate if changes were made. The images or other third party material in this article are included in the article's Creative Commons licence, unless indicated otherwise in a credit line to the material. If material is not included in the article's Creative Commons licence and your intended use is not permitted by statutory regulation or exceeds the permitted use, you will need to obtain permission directly from the copyright holder. To view a copy of this licence, visit http://creativecommons.org/licenses/by$\mathrm{nc} / 4.0 /$.

\section{REFERENCES}

1. Mohan SV, Chang ALS. Advanced basal cell carcinoma: epidemiology and therapeutic innovations. Curr Dermatol Rep. 2014;3(1):40-5.

2. Basset-Seguin N, Hauschild A, Kunstfeld R, et al. Vismodegib in patients with advanced basal cell carcinoma: primary analysis of STEVIE, an international, open-label trial. Eur J Cancer. 2017;86:334-48.

3. Scalvenzi M, Villani A, Mazzella C, Cappello M, Salvatores GD, Costa C. Vismodegib treatment in a HIV positive patient on antiretroviral therapy. Indian J Dermatol Venereol Leprol. 2018;84:758-60.

4. Girardi D, Barrichello A, Fernandes G, Pereira A. Targeting the Hedgehog pathway in cancer: current evidence and future perspectives. Cells. 2019;8(2): E153.

5. Villani A, Fabbrocini G, Cappello M, Costa C, Scalvenzi $M$. Real-life effectiveness of vismodegib in patients with metastatic and advanced basal cell carcinoma: characterization of adverse events and assessment of health-related quality of life using the Dermatology Life Quality Index (DLQI) test. Dermatol Ther (Heidelb). 2019;9(3):505-10.

6. Lacouture ME, Dreno B, Ascierto PA, et al. Characterization and management of hedgehog pathway inhibitor-related adverse events in patients with advanced basal cell carcinoma. Oncologist. 2016;21: 1218-29.

7. Drèno B, Kunstfeld R, Hauschild A, et al. Two intermittent vismodegib dosing regimens in patients with multiple basal-cell carcinomas (MIKIE): a randomised, regimen-controlled, double-blind, phase 2 trial. Lancet Oncol. 2017;18:404-12.

8. Scalvenzi M, Costa C, Cappello M, Villani A. Reply to Woltsche N. et al. Managing adverse effects by dose reduction during routine treatment of locally advanced basal cell carcinoma with the hedgehog inhibitor vismodegib: a single-centre experience. J Eur Acad Dermatol Venereol. 2019;33(4):e145-7. https://doi.org/10.1111/jdv.15469. 